\title{
Assessing Concept Generation Intervention Strategies for Creativity Using Design Problems in a Freshman Engineering Graphics Course
}

\author{
Dr. Raghu Pucha, Georgia Institute of Technology
}

Dr. Raghu Pucha is a Senior Lecturer at the Woodruff School of Mechanical Engineering, Georgia Institute of Technology, in the area of CAD/CAE and Manufacturing. Dr. Pucha teaches computer graphics and design courses at Georgia Tech., and conducts research in the area of developing computational tools for the design, analysis and manufacturing of advanced materials and systems. Dr. Pucha has three provisional U.S. patents and co-authored over 60 research papers. He is honored with Undergraduate Educator Award in 2012 and Geoffrey G. Eichholz Faculty Teaching Award in 2015 from the Center for Enhancement of Teaching and Learning (CETL) at Georgia Tech.

\section{Bryan Levy, Georgia Institute of Technology}

Bryan Levy is a graduate student at Georgia Institute of Technology. He obtained his Bachelor's degree from Georgia Tech and is currently obtaining a Master's degree from the same institute. His research primarily focuses in the impact of maker spaces on students and design problem equivalency as it pertains to assessing creativity.

\section{Dr. Julie S. Linsey, Georgia Institute of Technology}

Dr. Julie S. Linsey is an Associate Professor in the George W. Woodruff School of Mechanical Engineering at the Georgia Institute of Technological. Dr. Linsey received her Ph.D. in Mechanical Engineering at The University of Texas. Her research area is design cognition including systematic methods and tools for innovative design with a particular focus on concept generation and design-by-analogy. Her research seeks to understand designers' cognitive processes with the goal of creating better tools and approaches to enhance engineering design. She has authored over 100 technical publications including twenty-three journal papers, five book chapters, and she holds two patents.

\section{Dr. Sunni Haag Newton, Georgia Institute of Technology}

Sunni Newton is currently a Research Associate II at the Georgia Institute of Technology in the Center for Education Integrating Science, Mathematics, and Computing (CEISMC). Her research focuses on assessing the implementation and outcomes of educational interventions at the K-12 and collegiate levels. She received her MS and Ph.D. in Industrial/Organizational Psychology from Georgia Tech in 2009 and 2013, respectively. She received her BS from Georgia Tech in 2006, double-majoring in Psychology and Management.

\section{Dr. Meltem Alemdar, Georgia Institute of Technology}

Dr. Meltem Alemdar is Associate Director and Senior Research Scientist at Georgia Tech's Center for Education Integrating Science, Mathematics, and Computing (CEISMC). Her research focuses on improving K-12 STEM education through research on curriculum development, teacher professional development, and student learning in integrated STEM environments. Her interests also include evaluation of K-12 STEM initiatives that target low income and minority students. Dr. Alemdar has experience evaluating programs that fall under the umbrella of educational evaluation, including K-12 educational curricula, K-12 STEM programs after-school programs, and comprehensive school reform initiatives. She received her Ph.D. in Research, Measurement and Statistics from the Department of Education Policy at Georgia State University (GSU).

\section{Dr. Tris Utschig, Kennesaw State University}

Dr. Tristan T. Utschig is Associate Director for Learning Sciences in the Center for Excellence in Teaching and Learning (CETL) and is Associate Professor of Nuclear Engineering at Kennesaw State University. Formerly, he was Assistant Director for CETL and the Office of Assessment at Georgia Tech, and prior 
that was a tenured Associate Professor of Engineering Physics at Lewis-Clark State College. Dr. Utschig consults with faculty across the university about bringing scholarly teaching and learning innovations into their classroom and assessing their impact. He has regularly published and presented work on a variety of topics including assessment instruments and methodologies, using technology in the classroom, faculty development in instructional design, teaching diversity, and peer coaching. Dr. Utschig completed his $\mathrm{PhD}$ in Nuclear Engineering at the University of Wisconsin-Madison. 


\section{Assessing concept generation intervention strategies for creativity using design problems in freshman engineering graphics course}

\section{Introduction}

In a learning-centered instruction $\operatorname{approach}^{(1)}$, faculty become designers of learning environments for students, facilitators of students' active learning, and modelers of expert thought processes. Students construct knowledge through gathering and synthesizing information and integrating it with the general skills of inquiry, communication, critical thinking and creative problem solving. The basic principle of modern cognitive theory is that the learner must be actively engaged in learning by making connections and organizing learning into meaningful concepts. With the instructor acting as a facilitator, many intervention strategies are being implemented in a freshman engineering graphics and visualization course at Georgia Tech; these include (i) Process-oriented activities for improved student engagement and performance and (ii) Process-oriented intervention for creative and critical thinking (see Figure 1). The fifteen-week course includes design ideation with freehand sketching and three-dimensional, constraint-based solid modeling and prototyping. A project-based approach, which includes design ideation and thinking in the context of individual and team projects, is incorporated to promote engaged learning. Design thinking is a creative process based on the generation of many ideas and the selection of really good ideas from the many. In order to do this it is necessary to think generatively and postpone judgements on the ideas that emerge. Encouraging students to think outside their usual ways of thinking ${ }^{(2)}$ is an important feature of the process since this can often lead to novel solutions. Design thinking involves a series of divergent and convergent steps. Proposed Unconventional Thinking in Engineering Design (UnTiED) ideation method and other structured ideation methods that involve a series of divergent and convergent steps which are introduced in freshman engineering design projects ${ }^{(3)}$. Process-oriented intervention strategies that are designed to teach metacognitive skills that support creativity are evaluated in encouraging students to think outside their usual ways of thinking. A rubric that combines both domain-specific and 
creativity-relevant skills is proposed and used to evaluate student projects ${ }^{(4)}$. Processoriented intervention approaches shown in Figure 1 are used to (i) accomplish the connection between the academic abstraction and hands-on concrete application of engineering design graphics, (ii) transfer the learning responsibility to and (ii) increase student engagement.
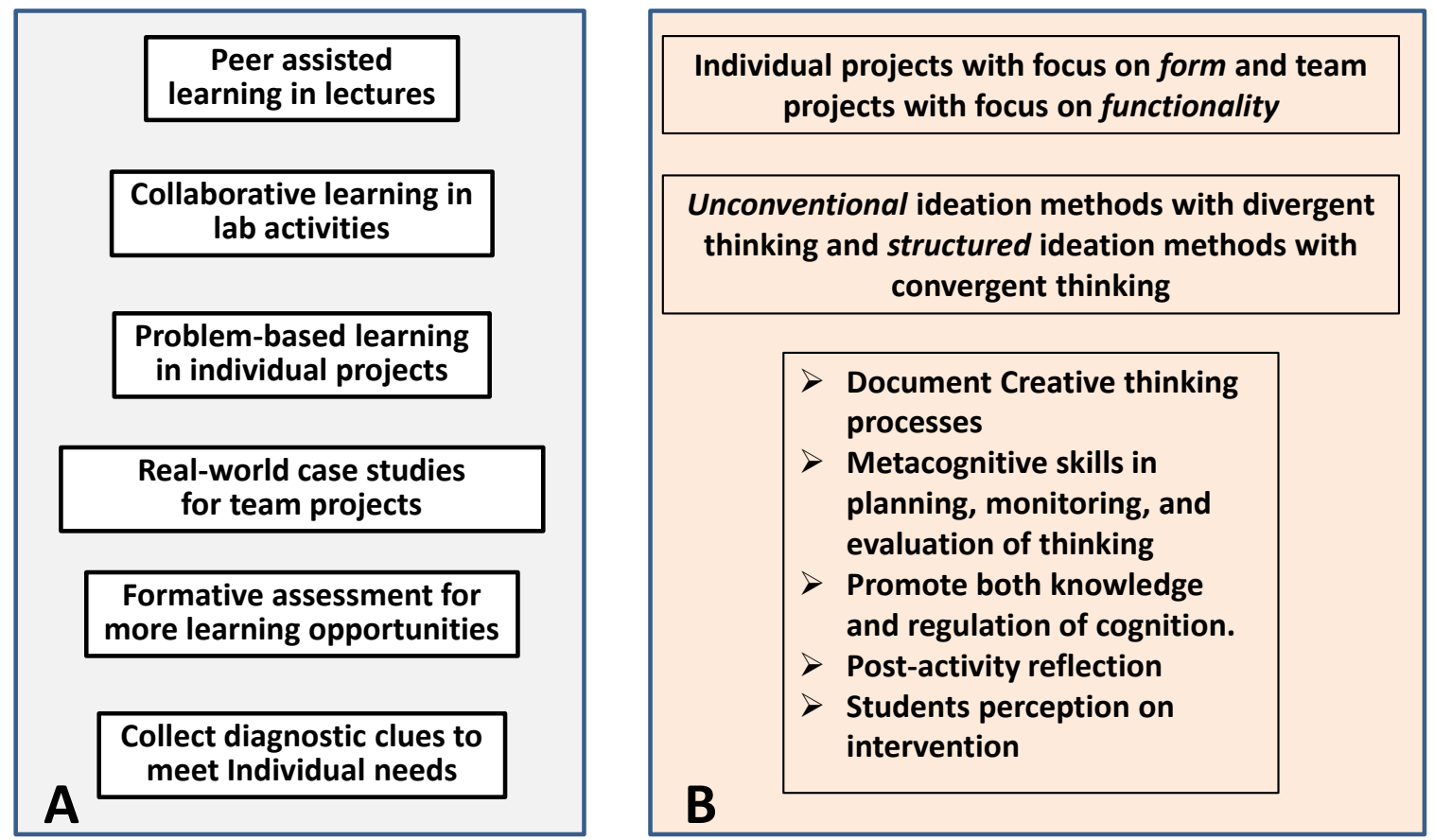

Figure 1: (A) Process-oriented activities for improved student engagement and performance and (B) Process-oriented intervention for creative and critical thinking

There is a lack of knowledge of instructional intervention strategies to help students be more creative. In this paper we discuss implementation and assessment of UnTiED ideation $_{\text {methods }}^{(3)}$ and design heuristics cards, which comprise a set of concept generation intervention strategies that support an iterative loop of divergent (creative) and convergent (critical) thinking within the context of a project-based learning environment in a freshman engineering graphics course. The four elements of UnTiED ideation, namely (i) random connections with unusual combinations between unrelated concepts, (ii) absurdity (pattern breaking thinking), (iii) tinkering with many nonjudgmental and open ended ideas, and (iv) questioning the status quo and challenging assumptions with reverse thinking, are initially introduced for ideation with divergent thinking. Students 
are also encouraged to use design heuristics cards for ideation with convergent thinking. These process-oriented creativity interventions are intended to help students' creative processes during engineering conceptual design and engaged learning of graphics and visualization tools.

To assess the above mentioned intervention strategies in terms of their impacts on engineering design, four design problems were selected from the literature ${ }^{(5)}$ and the students were given 50 minutes to generate as many solutions as possible using an unguided method; they could not use any outside tools. The solutions were then scored according to metrics developed ${ }^{(5)}$. The students were also given a survey at the beginning and end of class that included an engineering design self-efficacy assessment previously designed $^{(6)}$.

This paper will present

(1) Results from a survey on student perceptions of ideation methods and data on students' reflection comments and design descriptions analyzed using an open-coding approach

(2) Assessment of students' creativity in individual project using the proposed creativity assessment rubric

(3) Quantity, quality, novelty, variety, and completeness of generated ideas for two test design problems

(4) Comparison of Self-Efficacy Motivation Scores, Self-Efficacy Confidence Scores, Self-Efficacy Success Scores and Self-Efficacy Anxiety Scores between the comparison and experimental groups

\section{Literature on framing of design problems, structure and characteristics of design problems}

Design research has postulated that the structure of the design problem plays a significant role in the corresponding solutions generated. Originally, the design problem was said to define the problem space, which in turn defines the possible solutions available for the 
participant to find ${ }^{(7)}$ using a rational. This was later refined to say that the "ill structured" nature of design problems forces the participant to solve the design problem in smaller temporary design spaces that are part of the larger solution space ${ }^{(8)}$. Alternatively, a theory was postulated by Schön that states that design is not a straightforward process but rather one that requires reflection ${ }^{(9)}$. In this way, the structure of the problem directly influences the results to a lesser extent than does the framework through which the designer formulates his/her solution. Similarly, the design process has been described as an adaptive process where the problem and solution space simultaneously co-evolve in an iterative process ${ }^{(10,11)}$. This theory is further explored by Dorst, who suggests that the design process can be better approximated by the relative expertise of the designer as opposed to the structure of the design problem itself ${ }^{(12)}$.

Further studies were conducted related to design problems and the role of their structure and underlying nature. Studies have shown that a design solution may be forecast to an extent based on the complexity of the problem in terms of size and coupling using Function- Behavior-Structure modeling ${ }^{(13-15)}$. A system was then outlined to help researchers understand how to track this complexity throughout the design process ${ }^{(16)}$. Additional research into problem formulation has led to other models being developed such as P-maps that try to account for the ill-defined structure of design problems ${ }^{(17)}$. The end goal of all of this research is to understand to what extent the design problem and the nuances of its language affect the solutions generated by the participants. To this end, Durand et al. have put forth a list of characteristics of the design problem that are believed to influence the design results, such as size, connectedness, and familiarity with the problem and solution spaces ${ }^{(18)}$. Other research has suggested that the semantics and writing style of the problem can have a non-negligible influence on the manner in which the problem is solved ${ }^{(19)}$. Due to the variety of the design problems and corresponding variety of results seen, it is apparent that this area requires further investigation.

\section{End of Semester Survey Results on Student perceptions on Creative intervention}

Two Experimental sections (A and B) used UnTiED ideation methods and two comparison sections (D and I) used brainstorming for ideation in individual projects. 


\section{Methodology}

Data were collected as part of an end of semester survey covering various components of the course. This 38 - 45 item online survey was administered to students in all four sections. The instructor taught ideation methods intended to enhance creativity to students in two of his four sections. The two sections in which the ideation methods were taught are considered the experimental sections; the other two sections, in which brainstorming was taught in place of the ideation methods, are considered the comparison sections. Experimental group students were asked six Likert-type items about their perceptions of the ideation methods, as well as one open-ended item about how they felt the ideation methods affected their level of creativity. Comparison group students were asked a single open-ended item about how they came up with creative ideas for their individual projects.

SurveyMonkey (www.surveyMonkey.com), online survey software, was used to collect data during the course labs. All surveys were administered at or near the beginning of each lab section, which took approximately 15 minutes to complete. A staff member introduced the survey, provided the link on the whiteboard, and monitored data collection in all sections. 138 complete responses were received across all four of this instructor's sections; the overall response rate among this instructor's students was $74.6 \%$ (this was comparable to the overall response rate across all instructors for this survey, which was $77.6 \%)$.

\section{Results}

Experimental vs. Comparison group representation

\begin{tabular}{|l|l|l|}
\hline Section & \# students & \% of students \\
\hline Experimental sections (A \& B) & 77 & 55.80 \\
\hline Comparison sections (D \& I) & 61 & 44.20 \\
\hline
\end{tabular}


Of the 138 students responding to the survey, slightly over half (55.8\%) were in the experimental group; the remaining students $(44.2 \%)$ were in the comparison group.

Gender composition by condition

\begin{tabular}{|l|l|l|l|l|l|}
\hline & \# Male & \% Male & \# Female & \% Female & Total \\
\hline $\begin{array}{l}\text { Experimental sections } \\
(\text { A \& B) }\end{array}$ & 61 & 79.22 & 16 & 20.78 & 77 \\
\hline $\begin{array}{l}\text { Comparison sections } \\
(\text { D \& I) }\end{array}$ & 43 & 70.49 & 18 & 29.51 & 61 \\
\hline
\end{tabular}

Both groups are comprised primarily of men, with roughly $80 \%$ of the experimental group and roughly $70 \%$ of the comparison group being male.

\section{Experimental group responses to items on ideation methods}

\begin{tabular}{|l|l|l|l|}
\hline Item & N & Mean & SD \\
\hline The ideation methods were useful & 77 & 4.17 & 1.11 \\
\hline $\begin{array}{l}\text { The ideation methods were } \\
\text { enjoyable }\end{array}$ & 77 & 3.75 & 1.09 \\
\hline $\begin{array}{l}\text { The ideation methods enhanced my } \\
\text { ability to think creatively }\end{array}$ & 77 & 4.00 & 1.22 \\
\hline $\begin{array}{l}\text { The ideation methods enhanced my } \\
\text { ability to think critically }\end{array}$ & 77 & 3.96 & 1.12 \\
\hline $\begin{array}{l}\text { The ideation methods improved my } \\
\text { overall performance on the design } \\
\text { assessments in this course }\end{array}$ & 77 & 4.01 & 1.16 \\
\hline $\begin{array}{l}\text { I will use the ideation methods in } \\
\text { later classes, even when they are not } \\
\text { directly assigned }\end{array}$ & 77 & 3.72 & 1.14 \\
\hline
\end{tabular}


Students provided generally positive feedback on the ideation methods, as mean responses on all six items are above 3.5, which represents the midpoint between the ends of the response scale ("Strongly Disagree" to "Strongly Agree"). Slightly lower mean responses were provided on items related to how enjoyable the methods were and the extent to which students say they will use the methods in later classes, suggesting that these represent potential areas for improvement in future instruction on these methods. But overall, the methods were fairly well-received by students and appear to have been effective in achieving the goal of promoting creative and critical thinking among students, at least from students' perspectives.

\section{Experimental group open-ended item}

Experimental group students were asked in an open-ended item to describe how the UnTiED ideation methods they used affected the level of creativity that they achieved with their design activities. Of the 77 experimental group students, 69 provided responses to the item. Roughly half of these responses were positive, while the other half were either mixed or negative. Themes emerging from the responses, as well as illustrative quotes for each theme, are presented below.

\section{Theme 1: Ideation methods increased creativity/thinking outside the box}

Students stated that the ideation methods had improved their creativity and had helped them to think outside the box.

- "The UnTied ideation methods forced me to think outside of the box. Anything I would design with them would have to be absolutely original."

- "It helped me think outside of the box, instead of going with the most obvious, straight-forward, cookie-cutter solution to the problem."

- "They motivated me to put high emphasis on creativity and to devote additional time to the creative process" 


\section{Theme 2: Ideation methods helped with bringing together unrelated ideas}

Students stated that the ideation methods had helped them generate new and creative ideas by helping them bring together unrelated ideas that they wouldn't have otherwise thought to combine.

- "I was stuck in the ideation phase for a while with my individual project but was able to think of a good product using UnTiED ideation. It helped me make connections between unrelated subjects."

- "I added components together that I didn't automatically associate with each other leading to a higher level of creativity."

- "The UnTiED ideation methods helped me to create an original and creative design through combining two seemingly random ideas."

Theme 3: Ideation methods provided a process/method/starting point for creative thinking

Students discussed how the ideation methods gave them a framework/process/set of steps for creative thinking, and provided a good starting point for creative thinking.

- "It gave me a starting point to change my ideas from rehashes of existing products to original designs. "

- "It enabled me to think in a new perspective by providing me with methods to formulate new ideas and methods to approach problems."

- "They did help [me] be more creative, because it gave me a specific method of thinking that led to creativity."

Theme 4: Ideation methods provided room for exploration

Students discussed how the ideation methods gave them room for exploration of various ideas with few constraints. They discussed how the ideation methods allowed them to 
brainstorm without being so tied to the feasibility of their ideas, encouraged them to be less critical of their ideas, and gave them the flexibility to play around with their ideas.

- "They allowed me to be less critical of my design ideas, and to better expand on the ideas that I used in the design process."

- "It allowed me the flexibility to play around with the shapes and designs of things while maintaining the intended functionality."

- "They helped me to not think of feasibility while brainstorming."

\section{Theme 5: Ideation methods did not enhance creativity}

Some students felt that the ideation methods did not enhance their creativity. Many students simply stated that they did not help, while others elaborated on why they were unhelpful. Some students felt the methods were not explained well or discussed sufficiently in class. Others felt that they already used similar methods, and some students said that they came up with an idea using a different methodology and then applied an ideation method in order to satisfy course requirements.

- "The UnTiED ideation methods in no way altered my creative thought process."

- "The UnTiED idealization methods were only somewhat helpful. They were fairly obvious in their structure, in such a way that I found I already included that style when trying to be creative, among others. Due to the assignment requiring us to use one of the specific methods, I personally found it more limiting than useful."

- "I still had a hard time thinking outside of the box. I felt that the UnTiED methods could have been more helpful with more examples and elaboration."

- "I found that I often developed a process and then went back and tried to find an UnTiED ideation method that fit it, instead of the correct approach. So, for me, it did not impact my creativity all that much."

- "The UnTiED ideation methods slightly helped with my level of creativity, but not that much. Honestly, I was a bit confused with their wording how exactly they should be applied." 


\section{Comparison group open-ended question}

Comparison group students were asked an open-ended question about how they came up with creative ideas during their work on their individual project. Further, they were asked to discuss whether they used brainstorming and/or any other methods." Of the 61 comparison group students, 60 provided responses to the question. Themes emerging from the responses, as well as illustrative quotes for each theme, are presented below.

Theme 1: Brainstorming was used to come up with creative ideas for individual project

Many students discussed using brainstorming as the technique they used to generate creative ideas for their individual projects. Some students discussed both brainstorming and other resources/methods.

- "I used mostly brainstorming methods that were taught in the class. Additionally, I took a sheet of paper and I just sketched a bunch of different things and took what I liked."

- "Just sat down and brainstormed. Thought of several ideas, chose the one I thought was the best"

- "brainstorming by thinking how I could alter an everyday item to be Georgia Tech Themed"

- "I did use brainstorming. I thought of a few different things I would've liked to make, and decided on mine based on it's uniqueness (it was a mini golf course for the desktop) and relative simplicity."

- "I brainstormed general ideas then developed each a little bit and compared the results"

Theme 2: Resources/methods other than brainstorming were used to come up with creative ideas for individual project 
Students discussed a variety of methods they used, considerations they incorporated, and resources they drew upon in order to generate creative ideas for their individual projects. These included online resources, discussions with family/friends, modifying an existing design, and designing something to satisfy a personal or market need. Students also discussed more practical considerations, such as the feasibility of a design or the constraints of the assignment. Some students discussed both brainstorming and other resources/methods. Some students discussed multiple resources/methods other than brainstorming.

- "brainstormed and looked up souvenir ideas on the web, tried to combine them with GT icons like Buzz and Tech Tower"

- "I reviewed the website given for example products, as well as looked online for other products to gain inspiration."

- "I discussed potential ideas with classmates and friends, and narrowed down the choices to a few ideas. I then chose one from the list based on its challenges in CADing and how feasible it would be to 3D print."

- "I had to talked to my dad a few days before we started the assignment and he was complaining about not having a good way to charge his Apple Watch so it gave me the idea of making something to fix that problem."

- "I began with considering what products already existed and thought about possible ways to improve them. From there, I narrowed the list of ideas by considering the constraints given to us for this project."

- "just thought about existing different home and office tools/souvenirs and how I could make them more interesting and useful. It was difficult brainstorming ways to get multiple parts"

- "For my individual project, I used research of previous products as well as thumbnail sketches to formulate my ideas."

- "I chose an idea that would not be extremely difficult (due to lack of time to work on it) but also not too easy (I still wanted a bit of a challenge)." 
- "I considered something I would want as a product based on what kind of stuff I couldn't find online but thought people would want, and then figured out ways to make it unique compared to other products of the same type."

\section{$\underline{\text { Students' reflection comments analyzed using open-coding approach }}$}

In spring 2016 a targeted activity to promote reflection on learning and instruction related to creativity in the design process was conducted in the experimental sections A and B. The reflection activity was a component of the individual project. A brief description of the project is provided below:

You are currently employed as a design engineer at a company, who is official partner of your university, which specializes in the manufacturing and sale of verity of souvenir

items. Your boss asks you to take the lead on ideating, sketching and CAD modeling of creative and unique souvenirs for Home \& office use or décor. You are encouraged to use both UnTiED ideation followed by design heuristics cards for creative ideation.

Each student is asked to submit a report with the following items

1. Briefly describe your idea

2. Which UnTiED ideation element did you use:

I. Design ideas by seeking random connections with unusual combinations between un-related concepts

II. Absurdity (pattern breaking thinking) and direct absurd ideas on the right track for discovering new ideas

III. Tinkering with many design ideas which are nonjudgmental and open ended

IV. Challenging assumptions with reverse thinking

3. Design Heuristics Cards used

4. Reflection on Ideation methods. Please describe your reflective thoughts on the following

I. Did UnTiED ideation method helped you to be more creative. Why? / Why not? 
II. How did design heuristics cards help you to improve your design idea?

III. Did both these ideation methods increase your interest in subject matter and engagement and appreciate the importance of sketching during design ideation?

Ninety-nine responses were received, with 49 responses from Section A and 50 responses from section B. Students' reflective comments were analyzed using open-coding approach where individual responses were parsed into comments representing unique thoughts which were given a code. Codes were then analyzed for overlap and the frequency of each resulting code was then counted to represent themes emerging from the data. Results for major themes from the data are displayed in Table 1. The top two sections of the table displays results for common themes in terms of the ways students found the UNTiED ideation methods and the design heuristic cards to be helpful. The lower two sections of the table break down which types of UNTiED ideation methods student mentioned using, and the top seven most commonly used design heuristic cards. In both cases the frequency represents the number of times the coded concept/item appeared in the student reflective comments.

Table 1: Results from open coding of student reflection in UNTiED ideation methods and Design Heuristic cards

\begin{tabular}{|c|c|}
\hline Theme & Frequency \\
\hline \multicolumn{2}{|l|}{ Ways students found UNTiED ideation methods to be helpful } \\
\hline Adding new features & 8 \\
\hline Method to follow & 8 \\
\hline Made design cooler & 7 \\
\hline \multicolumn{2}{|l|}{ Ways students found Design Heuristic cards to be helpful } \\
\hline Thinking creatively & 24 \\
\hline Used to design & 12 \\
\hline Produced new/unusual features & 10 \\
\hline \multicolumn{2}{|l|}{ UNTiED ideation methods used } \\
\hline $\begin{array}{llll}\text { Seeking random } & \text { connections } & \text { with } & \text { unusual } \\
\text { combinations } & & & \end{array}$ & 52 \\
\hline
\end{tabular}




\begin{tabular}{|l|l|}
\hline Tinkering (many open ended design ideas) & 18 \\
\hline Absurdity & 17 \\
\hline Challenging assumptions with reverse thinking & 8 \\
\hline Design heuristic cards most often used & 19 \\
\hline \multicolumn{2}{|l|}{ Make components attachable/detachable } \\
\hline Add to existing product & 17 \\
\hline Allow user to assemble & 13 \\
\hline Allow user to customize & 12 \\
\hline Multifunctional & 11 \\
\hline Utilize inner space & 10 \\
\hline Use common base & 10 \\
\hline
\end{tabular}

Additionally, there were 11 student comments representing feelings of a lack of clarity about project expectations or instructions, 3 comments about this type of creative work being hard, and 7 comments indicating that student found "ideation" to something they enjoyed practicing.

Finally, another, separate, open coding analysis was conducted on the comments included in the end-of-term course surveys about student reactions to instruction. Results were analyzed only for the experimental sections of the course. 79 survey responses included student comments about the course. Of these, thirty comments (38\%) directly mentioned creativity, with some mentioning multiple aspects of creativity. Five major themes emerged from this analysis. Table 2 displays the results.

Table 2: Analysis of end-of-course survey comments about creativity

\begin{tabular}{|l|l|}
\hline Themes emerging from comments about course & Frequency \\
\hline Allowed/encouraged creativity & 6 \\
\hline Choice/freedom/ownership & 16 \\
\hline Great way to learn & 3 \\
\hline Fun/exceiting/gererates enthusiasm & 7 \\
\hline Multiple stages of design & 5 \\
\hline
\end{tabular}




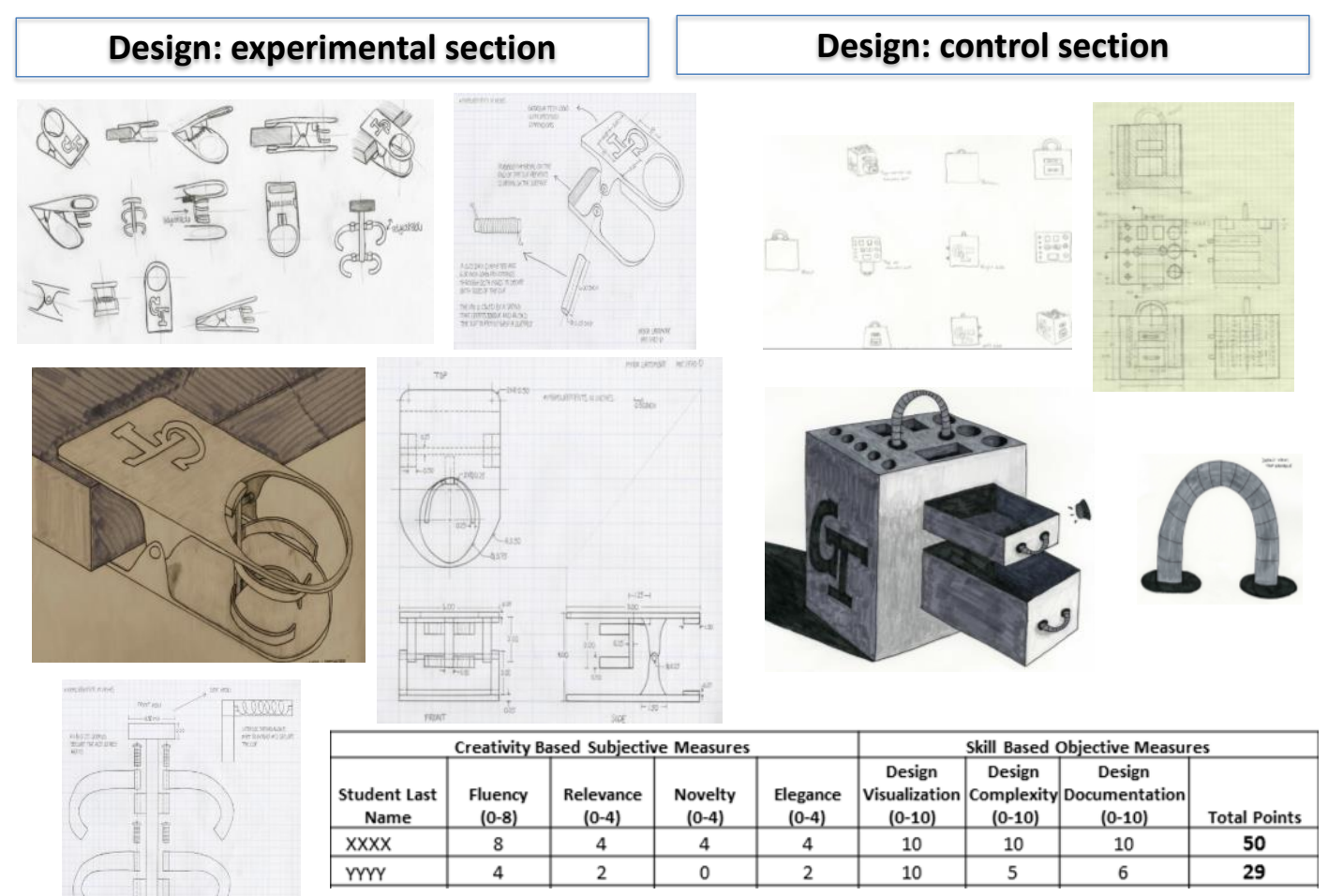

Figure 2: Creativity assessment rubric

\section{Assessment of students' individual projects creativity using the proposed rubric}

The componential model of creativity ${ }^{(20,21)}$ predicts that three major components contribute to creativity: domain-specific skills, general creativity-relevant skills (crossdomain), and task motivation. A creativity assessment rubric ${ }^{(3)}$ that combines both domain-specific and creativity-relevant skills is used to assess student designs in both experimental and comparison sections. The rubric items include both subjective and objective measures of various domain-specific and domain-general aspects.

\section{$\underline{\text { Test Design Problems and evaluation metrics }}$}

\section{Ideation Testing}

Ideation and creativity were measured through an idea generation session during one of their lab times. Participants were given a design problem and two minutes to read the problem, followed by 48 minutes to generate as many solutions as possible to the problem with a solution format of a sketch and accompanying description. The students 
were not allowed to use outside stimulus during this time. As this study was conducted in parallel with another study that looks at problem similarity, four different design problems were used and distributed evenly across participants with the distribution seen in Table 3 after any data was removed for test violations such as phone use or talking. The problems used were taken from literature and will be referred to in this paper as peanut, corn, alarm, and coconut due to the content of the problems ${ }^{(22)}$.

Table 3. Problem Sample Size

\begin{tabular}{|c|c|c|c|c|c|}
\hline Section & Peanut & Corn & Coconut & Alarm & Total: \\
\hline A & 11 & 8 & 8 & 8 & 35 \\
\hline B & 11 & 12 & 12 & 12 & 47 \\
\hline Experimental & $\mathbf{2 2}$ & $\mathbf{2 0}$ & $\mathbf{2 0}$ & $\mathbf{2 0}$ & $\mathbf{8 2}$ \\
\hline D & 9 & 10 & 8 & 7 & 34 \\
\hline I & 10 & 10 & 9 & 10 & 39 \\
\hline Comparison & $\mathbf{1 9}$ & $\mathbf{2 0}$ & $\mathbf{1 7}$ & $\mathbf{1 7}$ & $\mathbf{7 3}$ \\
\hline Total: & $\mathbf{4 1}$ & $\mathbf{4 0}$ & $\mathbf{3 7}$ & $\mathbf{3 7}$ & $\mathbf{1 5 5}$ \\
\hline
\end{tabular}

Upon completion of the idea generation activity, the submissions were graded according to the refined ideation metrics presented by Linsey ${ }^{(23)}$. The metrics used in this study were Quantity, Quality, Novelty, Variety, and Number of Solutions.

\section{Quantity}

The quantity metric used measures the number of unique features presented by the participant. This metric is calculated by counting the number of non-redundant features or ideas present across all solutions of a participant.

\section{Quality}

The quality metric is graded according to a 3-point scale variant developed by Linsey et. al. ${ }^{(24)}$. In this scale, a zero is assigned to a solution that is deemed not feasible from a technical standpoint, or if its implementation would not solve the fundamental problem put forth. A one is awarded to solutions that would solve the fundamental problem but would not satisfy all of the customer needs, and a two is awarded to solutions that solve the problem and meet most if not all of the customer needs. The quality metric reported is the average quality score produced by the participant. 


\section{Novelty}

The novelty metric is a measure of the uniqueness of a solution with respect to other solutions generated for the same design problem during that idea generation session ${ }^{25}$, ${ }^{26)}$. The metric utilizes a bin system where solutions are sorted into one or more problem specific bins. Once all solutions for the session are binned, each bin is assigned a novelty score according to the following equation.

$$
\text { Novelty }=1-\frac{\# \text { of ideas in bin }}{\text { Total } \# \text { of ideas binned }}
$$

The novelty score of individual solutions can then be found by averaging the novelty values of all the bins the solution uses. The novelty metric is the average novelty score of the participant and is calculated by averaging the novelty values of all the participant's solutions.

\section{Variety}

The variety metric utilizes the same bin list as the novelty metric to measure how much

of the solution space is explored by each participant ${ }^{(25,26)}$. The metric is calculated by comparing the total number of bins used by a participant to the total number of bins associated with the problem as seen in the following equation.

$$
\text { Variety }=\frac{\text { Number of bins a participant used }}{\text { Total number of bins }}
$$

\section{Number of Solutions}

The number of solutions metric measures the total number of complete concepts generated by the participant. This measure is unique from the quantity metric in that it looks at the entire concept instead of just features within the concepts.

\section{Results}

As different design problems were used during the idea generation session, this study presents the results for individual problems. Inferences can then be made across all design problems about the effects of variables such as the introduction of design heuristics. Before formal comparisons could be made on the effects of teaching design heuristics, the data was first analyzed for differences between individual sections. In doing this, it was found that the novelty metric for the coconut problem was statistically 
different according to an ANOVA ( $\mathrm{F}=2.820, \mathrm{p}=0.037)$. However, when coupled with the significance of a Kruskal-Wallis $\mathrm{H}$ test $\left(\mathrm{X}^{2}=9.117, \mathrm{p}=0.058\right)$ which accounts for irregularities in the data, the significance is considered by the author to be borderline. The section data was then combined according to their treatment, providing larger sample sizes.

The effect of teaching design heuristics could now be investigated. The groups were first checked for normality and equal variance using the Shapiro-Wilks and Levene's Test respectively. As there were only two groups in comparison, an independent samples t-test was used for analysis as well as a Mann-Whitney U Test to account for instances when the assumptions for the t-test were not met. The comparison was again made within each problem with the results seen in Table 4.

Table 4. Design Heuristics Comparison

\begin{tabular}{|c|c|c|c|c|c|c|}
\hline \multirow{2}{*}{\multicolumn{2}{|c|}{ Treatment Comparison }} & \multicolumn{3}{|c|}{ Independent Samples t-test } & \multicolumn{2}{|c|}{ Mann-Whitney U } \\
\hline & & $\mathbf{t}$ & df & Sig. (2-tailed) & $\mathbf{U}$ & Asymp. Sig. (2-tailed) \\
\hline \multirow{5}{*}{ Е } & Quantity & 1.516 & 39 & 0.138 & 149.500 & 0.118 \\
\hline & Quality & 1.355 & 39 & 0.183 & 157.500 & 0.172 \\
\hline & Novelty & 1.337 & 39 & 0.189 & 163.000 & 0.229 \\
\hline & Variety & 3.010 & 39 & 0.005 & 120.000 & 0.017 \\
\hline & Number of Solutions & 2.422 & 39 & 0.020 & 117.000 & 0.015 \\
\hline \multirow{5}{*}{ نِ } & Quantity & -0.170 & 38 & 0.866 & 196.500 & 0.924 \\
\hline & Quality & 0.540 & 38 & 0.593 & 170.000 & 0.410 \\
\hline & Novelty & -1.318 & 38 & 0.195 & 143.500 & 0.126 \\
\hline & Variety & -0.787 & 38 & 0.436 & 176.500 & 0.519 \\
\hline & Number of Solutions & -1.435 & 38 & 0.160 & 160.500 & 0.277 \\
\hline \multirow{5}{*}{$\begin{array}{l}\vec{\Xi} \\
\dot{\Xi} \\
\dot{0}\end{array}$} & Quantity & 1.197 & 35 & 0.239 & 142.000 & 0.392 \\
\hline & Quality & 0.651 & 35 & 0.519 & 147.000 & 0.481 \\
\hline & Novelty & -0.219 & 35 & 0.828 & 165.500 & 0.891 \\
\hline & Variety & 1.147 & 35 & 0.259 & 159.000 & 0.733 \\
\hline & Number of Solutions & 0.870 & 35 & 0.390 & 153.500 & 0.611 \\
\hline \multirow{5}{*}{$\stackrel{\Xi}{\frac{\pi}{Z}}$} & Quantity & -0.984 & 35 & 0.332 & 147.000 & 0.482 \\
\hline & Quality & 1.380 & 35 & 0.176 & 139.000 & 0.343 \\
\hline & Novelty & -0.359 & 35 & 0.722 & 161.500 & 0.796 \\
\hline & Variety & -0.391 & 35 & 0.698 & 169.000 & 0.975 \\
\hline & Number of Solutions & -0.315 & 35 & 0.755 & 166.500 & 0.914 \\
\hline & Key & \multicolumn{5}{|c|}{ Statistically Different } \\
\hline
\end{tabular}

As can be seen in the table, there are statistically significant differences in the variety and number of solutions metrics for the Peanut problem. This says that the group that was not exposed to the treatment (design heuristics) produced more solutions and solutions of a higher variety than those exposed to the treatment. Additionally, the data 
was graphed to get a more complete understanding with the results seen in Figure 3 . The data is graphed with error bars representing standard error.

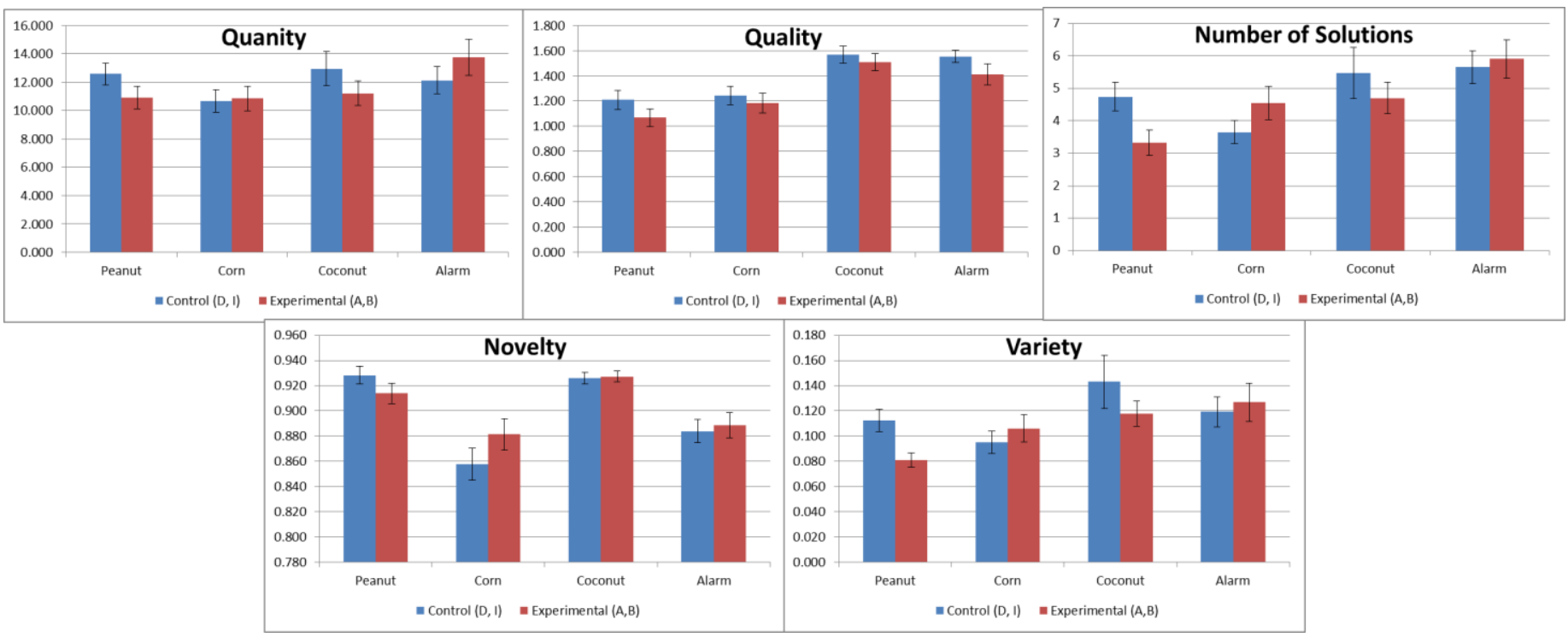

Figure 3. Design Heuristics Comparison

Upon closer inspection of the data, the difference is most likely caused from the comparison group in one class section, Section I, performing higher in these metrics. As this difference was only seen in the Peanut problem, and the cause most likely traced back to an individual class and not the treatment, the effect of teaching design heuristics on creativity can be seen as negligible.

However, during this idea generation session, the students were restricted from the use of outside variables including design heuristics cards. This restriction means the method could not be employed as intended with visual cues. Therefore, the result is more indicative of the long-term impact of exposing the method to the participants than the impacts of directly utilizing the method. Additionally, it was not observed if particular heuristics were more common amongst the experimental group, and how the participants generated their solutions. This would give greater insights into the effects of teaching design heuristics on creativity. 


\section{Summary and future work}

The learning - centered teaching and learning strategies, along with process oriented creativity intervention strategies, implemented in a freshman graphics and visualization course are presented. During the ideation stage of students' design projects in experimental sections, (i) UnTiED ideation methods and (ii) design heuristics cards were introduced with systematic instructions. The effect of these intervention strategies are evaluated and assessed through (i) theme-based analysis of survey results (ii) analysis of students' reflective comments using open-coding approach (iii) assessment of student's projects using proposed creative assessment rubric and (iv) test design problems in assessing the quantity, quality, novelty, variety, and completeness of generated ideas for the design problems and (v) comparison of self-efficacy motivation scores, self-efficacy confidence scores, self-efficacy success scores and self-efficacy anxiety Scores between the comparison and experimental groups. Future work includes, data collection and analysis of test design problems with explicit use of UnTiED ideation methods and design heuristics cards during idea generation. 


\section{References}

1. Pucha, R. V., and Utschig, T. T. (2012) Learning-Centered Instruction of Engineering Graphics through Real-world Problems and Case Studies, Journal of STEM Education 13, 24-33.

2. Hargrove, R. A. (2008) Creating creativity in the design studio: assessing the impact of metacognitive skill development on creative abilities, In College of Design, North Carolina State University, . North Carolina.

3. Pucha, R., Utschig, T. T., Newton, S. H., Alemdar, M., \& Moore, R., \& Noyes, C. R. (2016) Critical and Creative Thinking Activities for Engaged Learning in Graphics and Visualization Course, In ASEE Annual Conference \& Exposition, New Orleans, Louisiana.

4. Pucha, R., Newton, S. H., Alemdar, M., and Utschig, T. T. . (2016) Process-Oriented Intervention and Reflection Strategies for Creativity in Student Design Projects, In 4th international conference on design creativity, Atlanta, GA.

5. Linsey, J. S., Tseng, I., Fu, K., Cagan, J., Wood, K. L., and Schunn, C. (2010) A Study of Design Fixation, Its Mitigation and Perception in Engineering Design Faculty, Journal of Mechanical Design 132, 041003-041003.

6. Carberry, A. R., Lee, H.-S., and Ohland, M. W. (2010) Measuring Engineering Design SelfEfficacy, Journal of Engineering Education 99, 71-79.

7. Newell, A., and Simon, H. A. (1972) Human problem solving, Vol. 104, Prentice-Hall Englewood Cliffs, NJ.

8. Simon, H. A. (1973) The structure of ill structured problems, Artificial intelligence 4, 181-201.

9. Schon, D. A. (1984) The reflective practitioner: How professionals think in action, Vol. 5126, Basic books.

10. Dorst, K., and Cross, N. (2001) Creativity in the design process: co-evolution of problemsolution, Design Stud 22, 425-437.

11. Maher, M. L., Poon, J., and Boulanger, S. (1996) Formalising design exploration as co-evolution, In Advances in formal design methods for $C A D$, pp 3-30, Springer.

12. Dorst, K. (2003) The problem of design problems, Expertise in design, 135-147.

13. Mathieson, J. L., Wallace, B. A., and Summers, J. D. (2010) Assembly time modeling through connective complexity metrics, In Manufacturing Automation (ICMA), 2010 International Conference on, pp 16-23, IEEE.

14. Ameri, F., Summers, J. D., Mocko, G. M., and Porter, M. (2008) Engineering design complexity: an investigation of methods and measures, Research in Engineering Design 19, 161-179.

15. Summers, J. D., and Shah, J. J. (2003) Developing measures of complexity for engineering design, In ASME 2003 International Design Engineering Technical Conferences and Computers and Information in Engineering Conference, pp 381-392, American Society of Mechanical Engineers.

16. Mathieson, J., Miller, M., and Summers, J. (2011) A Protocol for Connective Complexity Tracking in the Engineering Design Process, In DS 68-7: Proceedings of the 18th International Conference on Engineering Design (ICED 11), Impacting Society through Engineering Design, Vol. 7: Human Behaviour in Design, Lyngby/Copenhagen, Denmark, 15.-19.08. 2011.

17. Dinar, M., Maclellan, C., Danielescu, A., Shah, J., and Langley, P. (2014) Beyond FunctionBehavior- Structure, In Design Computing and Cognition'12, pp 511-527, Springer.

18. Durand, F., Helms, M. E., Tsenn, J., McAdams, D. A., and Linsey, J. S. (2015) In Search of Effective Design Problems for Design Research, In ASME 2015 International Design Engineering Technical Conferences and Computers and Information in Engineering Conference, pp V007T006A011-V007T006A011, American Society of Mechanical Engineers.

19. Kumar, V., and Mocko, G. (2016) Similarity of Engineering Design Problems to Enable Reuse in Design Research Experiments, V007T006A042.

20. Amabile, T. M. (1983) The social psychology of creativity: A componential conceptualization, Journal of Personality and Social Psychology 45, 357-376.

21. Conti, R., Coon, H., and Amabile, T. M. (1996) Evidence to Support the Componential Model of Creativity: Secondary Analyses of Three Studies, Creativity Research Journal 9, 385-389.

22. Levy, B., Hilton, E., Tomko, M., and Linsey, J. ( 2017) Investigating Problem Similarity through Study of Between-Subject and Within-Subject Experiments (accepted), In ASME IDETC, Cleveland, $\mathrm{OH}$. 
23. Linsey, J. S., Green, M. G., Murphy, J., Wood, K. L., and Markman, A. B. (2005) "Collaborating To Success": An Experimental Study of Group Idea Generation Techniques, In ASME 2005 International Design Engineering Technical Conferences and Computers and Information in Engineering Conference, pp 277-290, American Society of Mechanical Engineers.

24. Linsey, J. S., Clauss, E., Kurtoglu, T., Murphy, J., Wood, K., and Markman, A. (2011) An experimental study of group idea generation techniques: understanding the roles of idea representation and viewing methods, J Mech Design 133, 031008.

25. Shah, J. J., Smith, S. M., and Vargas-Hernandez, N. (2003) Metrics for measuring ideation effectiveness, Design Stud 24, 111-134.

26. Nelson, B. A., Wilson, J. O., Rosen, D., and Yen, J. (2009) Refined metrics for measuring ideation effectiveness, Design Stud 30, 737-743. 